\title{
Effect of Scale-Aware Nonlocal Planetary Boundary Layer Scheme on Lake-Effect Precipitation at Gray-Zone Resolutions
}

\author{
HYUN-JOO CHOI ${ }^{\mathrm{a}}$ AND JI-YOUNG HAN ${ }^{\mathrm{b}}$ \\ Korea Institute of Atmospheric Prediction Systems, Seoul, South Korea
}

(Manuscript received 27 August 2019, in final form 2 May 2020)

\begin{abstract}
The effects of a nonlocal planetary boundary layer (PBL) scheme that considers scale dependency in the parameterized turbulent vertical transport are investigated for a case of wintertime lake-effect precipitation over Korea at gray-zone resolutions using a mesoscale model. An experiment using the scale-aware PBL scheme is compared with that using a conventional PBL scheme, which shows that the simulated precipitation amount at a resolution of less than $1 \mathrm{~km}$ is smaller with the scale-aware PBL scheme. The role of turbulent processes in simulating lake-effect precipitation is understood through interaction with microphysical processes. When the scale-aware PBL scheme is used, liquid water content is increased while ice water content is reduced. The higher cloud water content is because of enhanced condensation with stronger updrafts, attributed to the suppression of parameterized turbulent mixing. This results in higher rainwater content by enhancing autoconversion and accretion from cloud water to rainwater. The cloud ice content is reduced mainly because of the suppressed deposition and enhanced sublimation centered near the PBL top, and the snow content is reduced mainly because of the enhanced sublimation below and near the PBL top and suppressed growth of cloud ice to snow. The lower ice water content is mainly due to the drier PBL, attributed to the enhanced resolved (suppressed parameterized) turbulent moisture transport and enhanced condensation. The melting of a smaller amount of snow under dominant cold rain processes is responsible for the reduced surface precipitation with the scale-aware PBL scheme.
\end{abstract}

\section{Introduction}

The planetary boundary layer (PBL) is the lowest part of the atmosphere, which is strongly affected by the underlying surface owing to rapid vertical mixing processes, mostly turbulence. Within the PBL, turbulent vertical transport plays a crucial role in the momentum, heat, and moisture budgets (Stull 1988). The temporal scale of turbulence is in the range of seconds to half an hour, and its length scale varies from milimeters for dissipative eddies to hundred meters for transporting eddies. Therefore, subkilometer grid sizes are needed to explicitly resolve atmospheric motions associated with turbulence. However, the horizontal resolutions of most current global and regional models for numerical

\footnotetext{
${ }^{a}$ Current affiliation: Numerical Modeling Center, Korea Meteorological Administration, Seoul, South Korea.

${ }^{\mathrm{b}}$ Current affiliation: School of Earth and Environmental Sciences, Seoul National University, Seoul, South Korea.
}

Corresponding author: Ji-Young Han, han0@snu.ac.kr weather prediction and climate simulations are insufficient to resolve turbulent motion. Thus, PBL parameterizations are required to represent the impact of subgrid-scale turbulent motion in the models.

In common simulations with coarse resolutions from several kilometers to tens of kilometers, turbulent vertical mixing is controlled only by the parameterizations. However, the increase in computing power has allowed for high-resolution simulations, in which the turbulence can be partly resolved. This has led to the "gray zone" issue for subgrid-scale PBL parameterizations, also called "terra incognita" (Wyngaard 2004). In the gray zone, the turbulence scale and model-resolvable minimum scale are comparable; thus, the turbulence is neither fully resolved nor fully parameterized. In particular, in convective boundary layers (CBLs), the turbulence length scale is in the order of a kilometer, resulting in errors associated with the gray-zone problem in simulations using conventional nonlocal PBL parameterizations with near-kilometer resolution (e.g., Petch et al. 2002; Bryan et al. 2003; Fiori et al. 2009; LeMone et al. 2010; Honnert et al. 2011; Ching et al. 2014; 
Shin and Dudhia 2016). Here, nonlocal PBL parameterizations represent nonlocal vertical transport by convective large eddies in addition to the local mixing by smaller eddies, which is given by a mass-flux term (e.g., Soares et al. 2004; Siebesma et al. 2007; Pergaud et al. 2009) or a gradient-adjustment gamma term (e.g., Deardorff 1972; Holtslag and Moeng 1991; Hong et al. 2006). With conventional PBL parameterizations, in which the turbulent mixing is considered as a completely subgrid-scale process, the parameterized nonlocal mixing at gray-zone resolutions is overestimated without being reduced by taking into account the resolved turbulent mixing, which results in weakened resolved motion (e.g., Honnert et al. 2011; Ching et al. 2014).

To overcome the gray-zone problem in high-resolution CBL simulations, some studies have introduced approaches representing partially resolved turbulent mixing at gray-zone resolutions (e.g., Boutle et al. 2014; Shin and Hong 2013, 2015; Efstathiou and Beare 2015; Ito et al. 2015; Honnert et al. 2016; Zhou et al. 2017; Kurowski and Teixeira 2018). Among these studies, Shin and Hong (2015) first evaluated the scale-aware PBL parameterization against both large-eddy simulation (LES) and real-case simulations [hereinafter we will refer to the parameterization discussed by Shin and Hong $(2013,2015)$ as SH]. They found that vertical motions and convective rolls are intensified in the subkilometer simulations with the scale-aware PBL parameterization. Since then, several studies have further investigated the effects of the $\mathrm{SH}$ parameterization and found that it performs better at gray-zone resolutions than its conventional parameterization of Hong et al. (2006), which scheme has been developed at Yonsei University and thus is named YSU hereinafter (e.g., Doubrawa et al. 2018; Xu et al. 2018). However, all of these studies consider dry CBLs; the scale-aware PBL parameterization has not been tested for moist CBLs, where PBL parameterizations interact strongly with microphysical processes within convection.

In this study, the effects of the scale-aware SH PBL scheme are investigated for a case of wintertime lakeeffect precipitation over Korea at gray-zone resolutions using the Weather Research and Forecasting (WRF) Model (Skamarock et al. 2008). An experiment with the scale-aware PBL scheme is performed, and the results from the experiment are compared with those using the conventional YSU PBL scheme. Furthermore, the role of the turbulent vertical transport in simulating precipitation is explored in aspects of interaction with microphysical processes.

This paper is organized as follows. Section 2 describes the model and experimental design, and section 3 presents the overview of the case examined in this study. The results for precipitation, background atmosphere, and turbulent and microphysical processes at a grayzone resolution from the experiments using the scale-aware and conventional PBL schemes are investigated in section 4 . The comparisons between the two experiments are also discussed in the same section. A summary and conclusions are provided in the last section.

\section{Model and experimental design}

\section{a. Model description}

The model used in this study is the WRF Model, version 3.9.1, with several physics schemes updated to version 4.0. The physics package includes the simplified Arakawa-Schubert deep convection scheme (Han and Pan 2011) updated by the Korea Institute of Atmospheric Prediction Systems (KIAPS) (e.g., Han et al. 2016; Kwon and Hong 2017; Han et al. 2020), the Global/Regional Integrated Model system (GRIMs) shallow convection scheme (Hong and Jang 2018), the WRF single-moment 5-class (WSM5) microphysics scheme (Hong et al. 2004), the Rapid Radiative Transfer Model for general circulation models [RRTMG; Iacono et al. 2008), improved by Baek (2017)], and the unified Noah land surface model (Chen and Dudhia 2001).

For the PBL parameterization, two schemes are adopted separately. One is the YSU scheme, which is a conventional PBL scheme that does not consider scale awareness in the gray zone. The other is the SH scheme, which is a scale-aware PBL scheme that considers the grid-size dependencies of subgrid-scale turbulent vertical transport in a CBL at gray-zone resolutions. The YSU scheme is a first-order closure scheme that parameterizes the vertical transport of subgrid-scale turbulent fluxes using prognostic mean variables through the vertical diffusion equation as follows:

$$
\frac{\partial C}{\partial t}=-\frac{\partial}{\partial z} \overline{w^{\prime} c^{\prime}}=\frac{\partial}{\partial z}\left[K_{c}\left(\frac{\partial C}{\partial z}-\gamma_{c}\right)-\overline{\left(w^{\prime} c^{\prime}\right)_{h}}\left(\frac{z}{h}\right)^{3}\right],
$$

where $C$ is the prognostic variable for zonal wind $u$, meridional wind $v$, potential temperature $\theta$, water vapor $q_{v}$, cloud water $q_{c}$, and cloud ice $q_{i} ; K_{c}$ is the diffusivity for mean variable $C$, which is based on the $K$ profile for the CBL and is a function of the local wind shear and local Richardson number in the free atmosphere; and $\gamma_{c}$ is the nonlocal gradient adjustment term for heat and momentum components to represent the nonlocal mixing by convective large eddies. The $\gamma_{c}$ is not employed for passive scalars (i.e., $q_{v}, q_{c}$, and $q_{i}$ ). The last term 
inside the square brackets of the right-hand side of Eq. (1) is an asymptotic entrainment flux term in the inversion layer, which is proportional to the surface flux. The PBL height is given by $h$.

In the SH scheme, the local and nonlocal heat transports are separately calculated by considering grid-size dependencies:

$$
\frac{\partial \theta}{\partial t}=-\frac{\partial}{\partial z}\left({\overline{w^{\prime} \theta^{\prime}}}^{L} P_{L}+{\overline{w^{\prime} \theta^{\prime}}}^{\mathrm{NL}} P_{\mathrm{NL}}\right)
$$

The local heat transport is formulated by multiplying a grid-size dependency function $P_{L}$ by the total local transport profile $\overline{w^{\prime} \theta^{\prime}}$, which is calculated using the eddy diffusivity formula [i.e., the first term in the square brackets of the right-hand side of Eq. (1)]. The nonlocal heat transport is formulated by multiplying a grid-size dependency function $P_{\mathrm{NL}}$, which is different from $P_{L}$, by the total nonlocal transport profile $\overline{w^{\prime} \theta^{\prime}} \mathrm{NL}$, which is obtained through linear fitting to the LES output maintaining the basic role of the nonlocal transport (i.e., surface-layer cooling, mixed-layer heating, and the entrainment). Note that the prescribed nonlocal transport profile is a complete change from the gradient-adjust gamma term in the conventional nonlocal $K$-profile models. The turbulent vertical transports of momentum, moisture, and cloud water and ice are computed by multiplying grid-size dependency functions with their total transport profiles. Detailed formulations of the $\mathrm{SH}$ scheme including the grid-size dependency functions can be found in Shin and Hong (2013, 2015).

\section{b. Experimental design}

The five nested domains employing one-way nesting are designed with horizontal resolutions of 27, 9, 3, and $1 \mathrm{~km}$ and $333 \mathrm{~m}$ to include the gray-zone resolution for the vertical transport in the PBL (Fig. 1). The numbers of horizontal grid points of the five domains are $178 \times$ $150,259 \times 223,463 \times 463,751 \times 751$, and $1201 \times 1201$, respectively. The outermost domain is centered at $38^{\circ} \mathrm{N}$, $125^{\circ} \mathrm{E}$ and covers the East Asian region. The finest domain is designed to include three islands (Heuksando, Hongdo, and Hataedo, marked as 1, 2, and 3, respectively) with the automatic weather station (AWS) observations located in the Yellow Sea (also known as the West Sea). The result analysis in the finest domain is performed in areas around the three islands marked with gray dots, except for domain edges (333-m-resolution analysis domain hereinafter). All domains use 51 vertical layers with the top at $50 \mathrm{hPa}$.

To investigate the effects of scale dependency in the parameterized turbulent vertical transport on precipitation at a gray-zone resolution, two experiments are conducted, separately considering the YSU (CTL experiment)

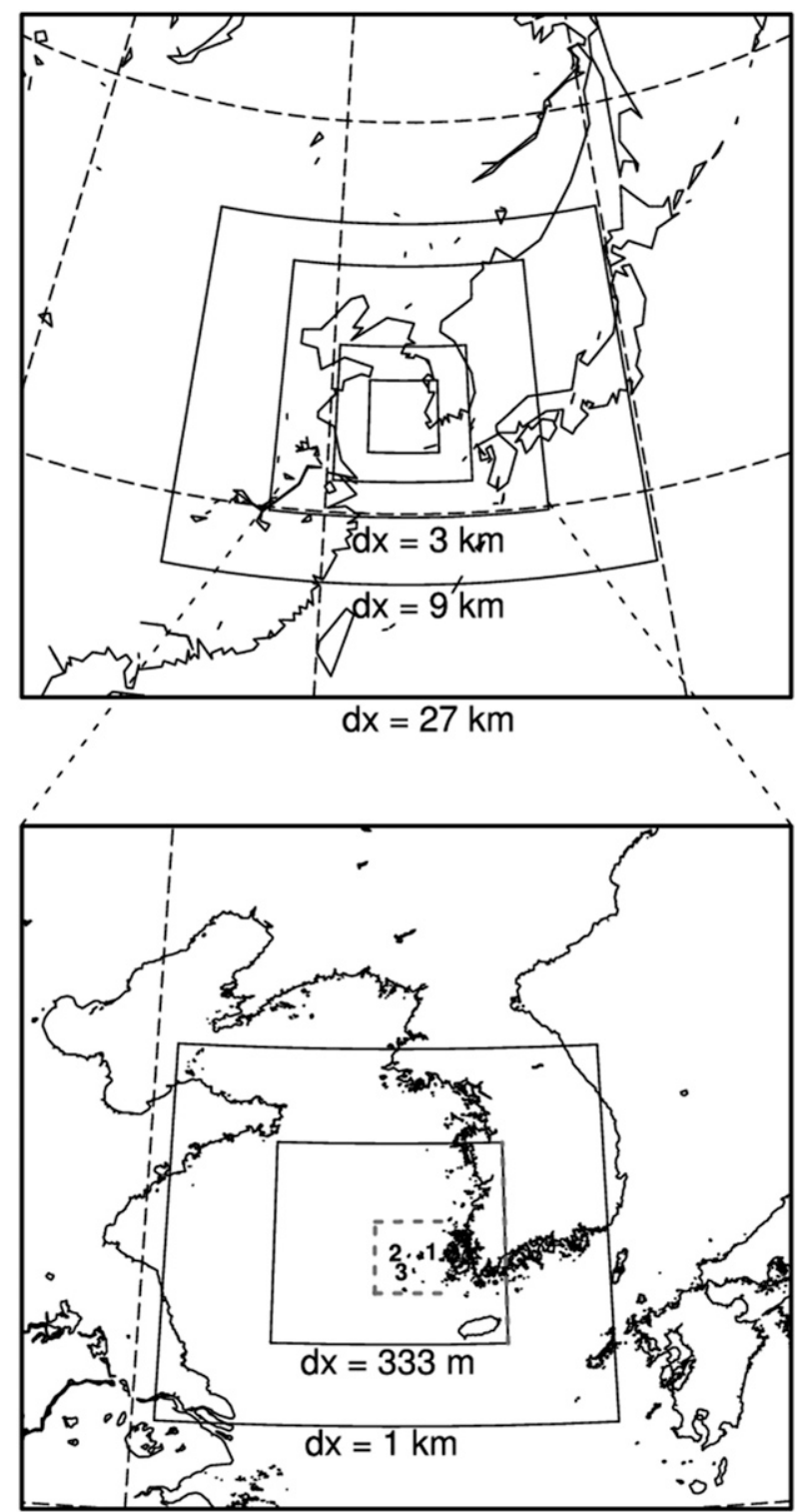

1-Heuksando, 2-Hongdo, 3-Hataedo

FIG. 1. Maps of the (top) 27-km-resolution domain with the nested 9-, 3-, and 1-km and 333-m-resolution domains, and (bottom) 3-km-resolution domain zoomed in. In the 333-m-resolution domain, the domain used for result analysis is plotted by a gray dash-outlined square. Three AWS observation points (Heuksando, Hongdo, and Hataedo) are plotted by number.

and SH (NEW experiment) schemes at a resolution of $333 \mathrm{~m}$ for the case of wintertime lake-effect precipitation over Korea. A 36-h forecast starting at 0000 UTC 18 December 2013 is performed for each experiment. For the domains of 27, 9, 3, and $1 \mathrm{~km}$, the YSU scheme is identically employed in both the CTL and NEW experiments to simplify the understanding of the results by limiting the effect of the scale awareness to subkilometer 

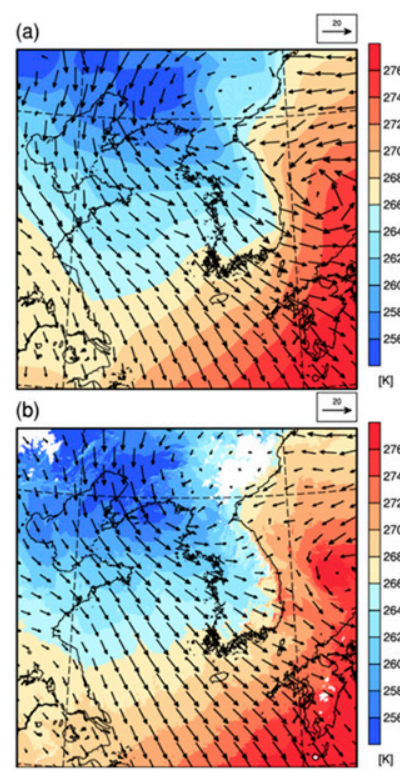

(c)

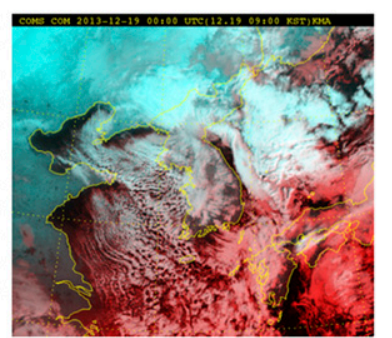

(e)

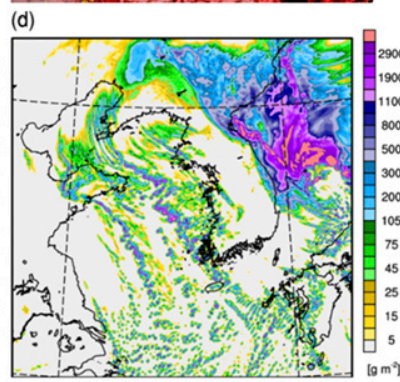

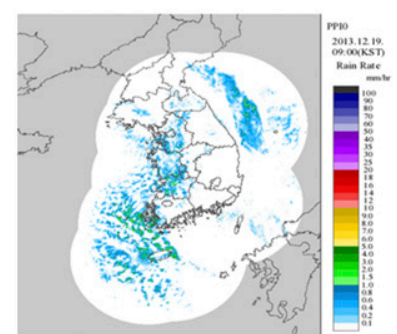

(f)

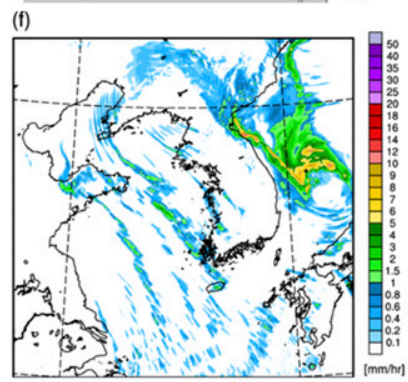

(g)

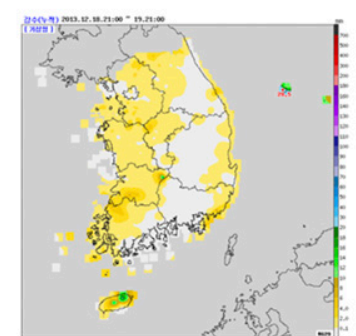

(h)

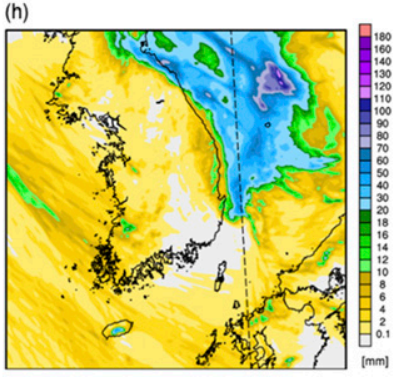

FIG. 2. The 900-hPa wind (arrows) and temperature (K; shading) from the (a) FNL data and (b) experiment, (c) cloud image from COMS, (d) total water path $\left(\mathrm{g} \mathrm{m}^{-2}\right)$ from the experiment, and precipitation rate $\left(\mathrm{mm} \mathrm{h}^{-1}\right)$ from the (e) radar observation and (f) experiment at 0000 UTC 19 Dec 2013, along with 24-h accumulated precipitation amount (mm) from the (g) AWS observation and (h) experiment for 1200 UTC 18-19 Dec 2013 in the 3-km-resolution domain.

resolution, because adopting the $\mathrm{SH}$ scheme in the outer domains also has little effect on the results in the innermost domain. When the $\mathrm{SH}$ scheme is adopted in all domains, its effects on precipitation and the differences from the CTL experiment are consistent with those when the scheme is adopted only in the innermost domain (not shown). For the initial and boundary conditions, the National Centers for Environmental Prediction (NCEP) Final Analysis (FNL) dataset with a horizontal resolution of $1^{\circ}$ at 6 -h intervals is used. Sea surface temperature (SST) forcing is obtained from the NCEP daily real-time global SST (RTG_SST) analysis with a horizontal resolution of $0.5^{\circ}$ (Thiébaux et al. 2003).

\section{Case overview}

Figures $2 \mathrm{c}$ and $2 \mathrm{e}$ display the cloud image from Communication, Ocean, and Meteorological Satellite $(C O M S)$ and precipitation rate from the radar observation, respectively, over Korea at 0000 UTC 19 December 2013, which show wave patterns associated with the lake effect in the West Sea of Korea. The lake-effect precipitation is induced by the large difference in temperature between the sea and the air above it, as the Siberian cold air mass expands above the West Sea that is warm due to the Kuroshio Current (Fig. 2a). The WRF simulation in the 3-kmresolution domain covering Korea, results of which are the same in both the CTL and NEW experiments, generally captures the observed large-scale features and wavy cloud and precipitation patterns (Figs. 2b,d,f). The amount of 24-h accumulated precipitation observed at the AWS sites located in the West Sea and the western part of the Korean Peninsula for 1200 UTC 18-19 December 2013 is approximately $10 \mathrm{~mm}$ (Fig. 2g), which is generally well simulated in the WRF experiment (Fig. 2h).

\section{Results}

In this section, the characteristics of precipitation related to lake effect and background atmosphere in the West Sea of Korea between the CTL and NEW experiments at 333-m resolution are compared. In addition, the differences between the two experiments are understood by investigating the characteristics of the turbulent and microphysical processes and the interaction between the two physical processes.

\section{a. Precipitation and background atmosphere}

Figures $3 \mathrm{a}$ and $3 \mathrm{~b}$ show the precipitation rates from the CTL and NEW experiments in the 333-m-resolution analysis domain at 0700 UTC 19 December 2013. Both experiments capture the observed wave patterns with phase lines oriented in the northwest-southeast direction related to the wind direction; however, the precipitation intensity in the NEW experiment is locally 
Precipitation rate (0700 UTC 19)

(a) CTL

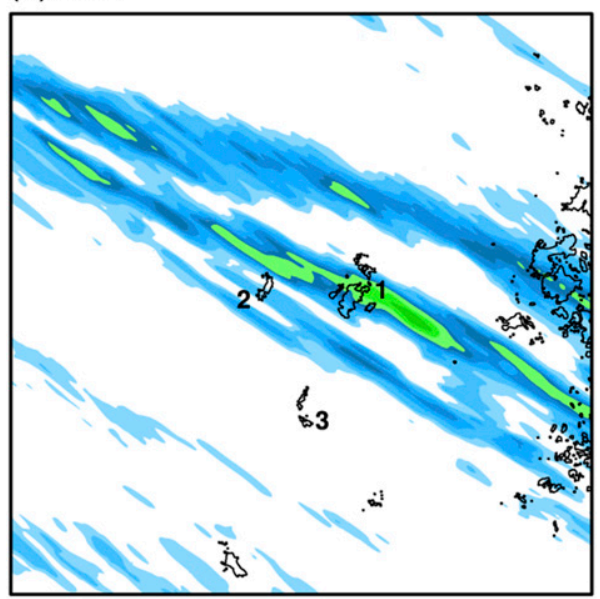

(b) NEW

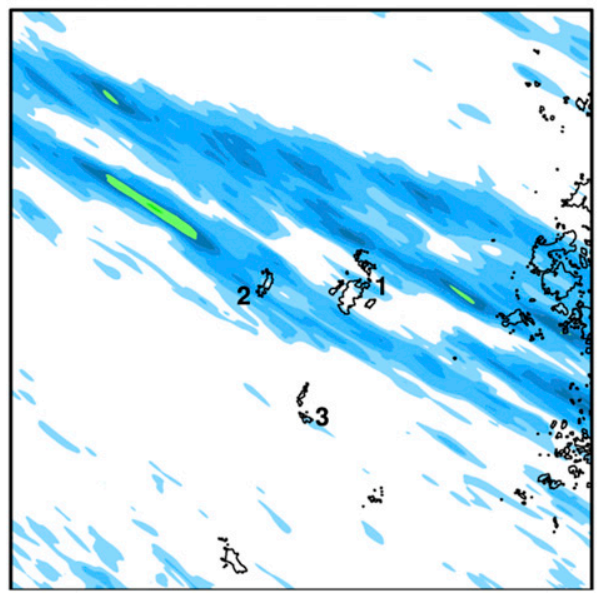

Accum. precipitation (1200 UTC 18-19)

(c) CTL

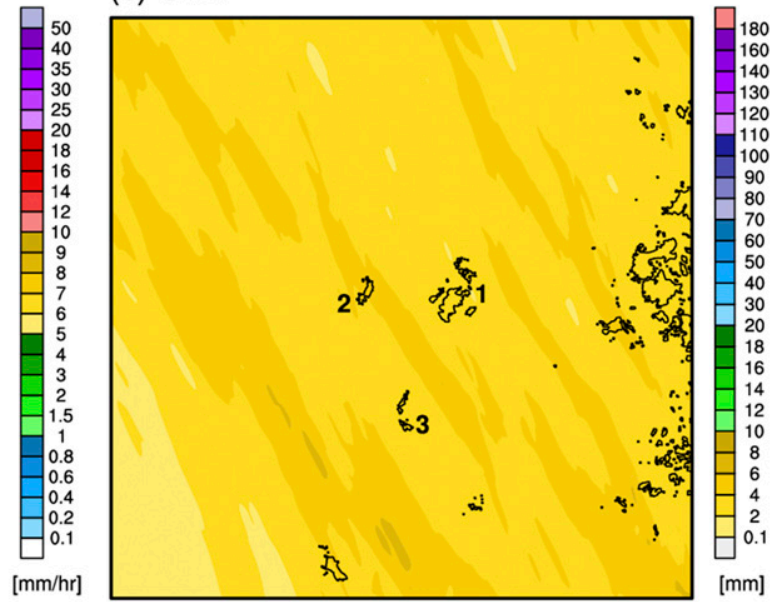

(d) NEW
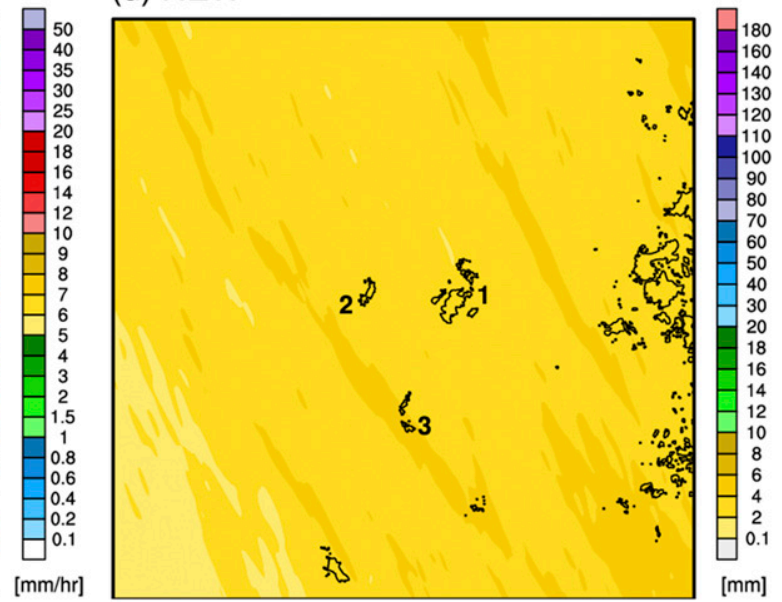

FIG. 3. Precipitation rate $\left(\mathrm{mm} \mathrm{h}^{-1}\right)$ from the (a) CTL and (b) NEW experiments in the 333-m-resolution analysis domain at 0700 UTC 19 Dec 2013, and the 24-h accumulated precipitation amount (mm) from the (c) CTL and (d) NEW experiments for 1200 UTC 18-19 Dec 2013.

weaker compared with that in the CTL experiment. The amount of 24-h accumulated precipitation for 1200 UTC 18-19 December 2013 is also less in the NEW experiment than that in the CTL experiment (Figs. 3c,d).

The time series of the precipitation rate averaged over the three AWS observation points 1) Heuksando, 2) Hongdo, and 3) Hataedo shown in Fig. 3 from the CTL and NEW experiments are compared with each other and with that from the AWS observations (Fig. 4a). Note that we display the precipitation rate averaged over three observations point for better visualization. The actual precipitation is observed during the period of 2300 UTC 18 December-0400 UTC 19 December 2013, and the peak occurs at 0000 UTC 19 December. Both experiments produce the peak of precipitation later than the observed one. The precipitation amount at the peak is much overestimated in the CTL experiment, while it is reduced in the NEW experiment. Figure $4 \mathrm{~b}$ shows the time series of the precipitation rate averaged over the 333-m-resolution analysis domain from the CTL and NEW experiments, which are consistent with the findings shown in Fig. 4a. The NEW experiment produces less precipitation than that of the CTL experiment, especially after 12 -h integration. The maximum difference between the two experiments occurs at 0700 UTC 19 December.

To understand the difference in precipitation between the CTL and NEW experiments the background fields from the two experiments are compared with each other. Figure 5 shows vertical velocities at a height of $1 \mathrm{~km}$ around the PBL top from the CTL and NEW experiments in the 333-m-resolution analysis domain at 
(a)

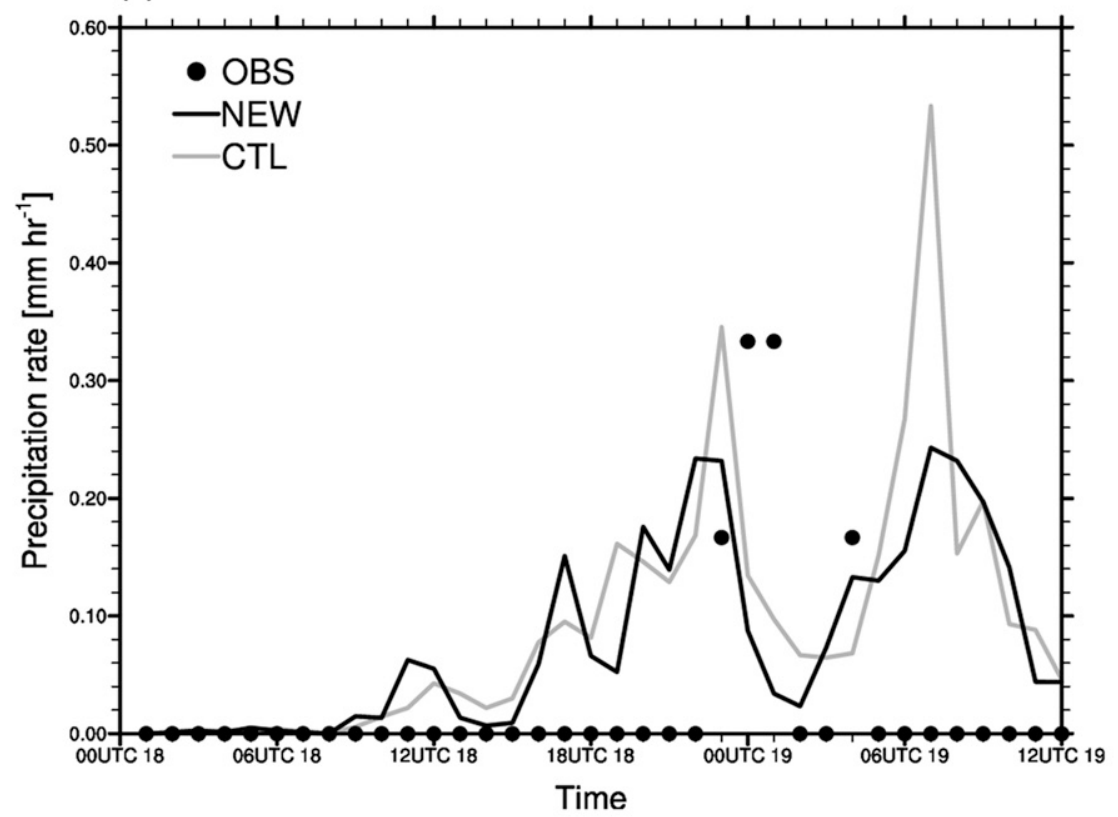

(b)

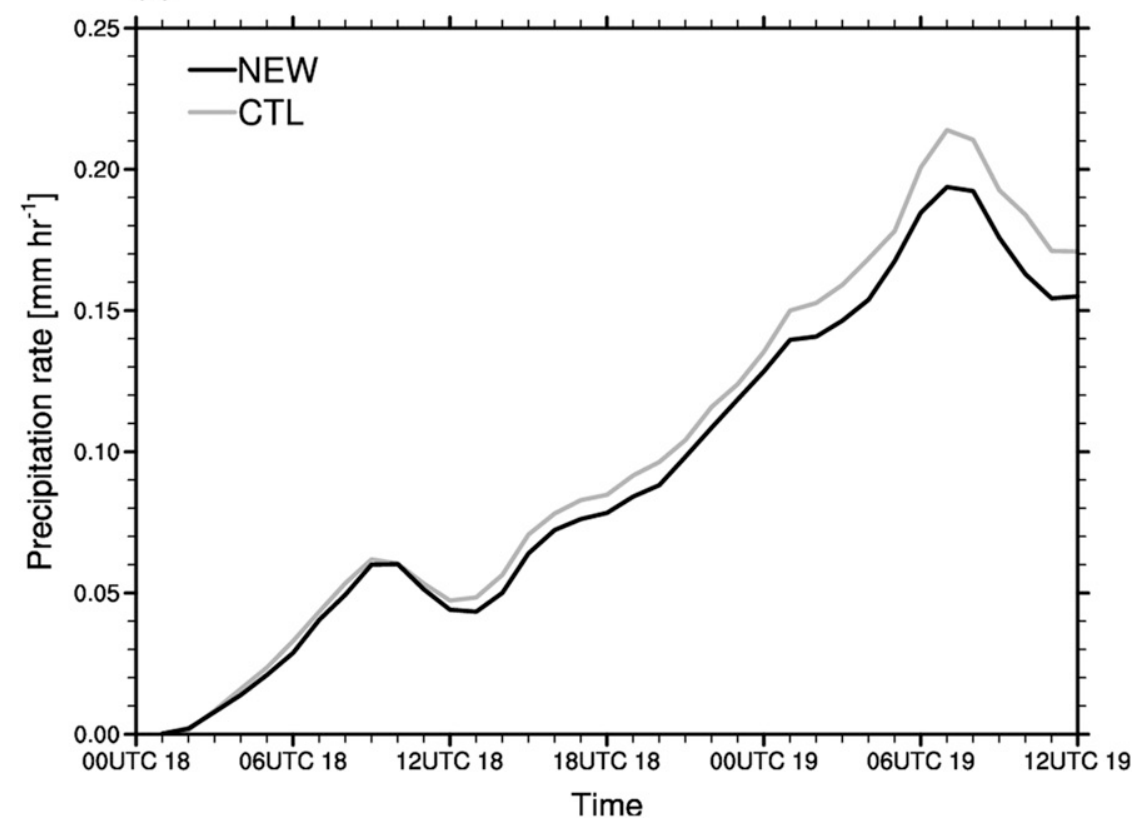

FIG. 4. Time series of precipitation rate $\left(\mathrm{mm} \mathrm{h}^{-1}\right)$ from the AWS observation (black circles) and CTL (gray line) and NEW (black line) experiments at 333-m resolution averaged over (a) the three AWS observation points shown in Fig. 1 and (b) the analysis domain.

0700 UTC 19 December 2013 when the maximum difference in precipitation amount occurs. The vertical velocity fields from both experiments show wave patterns with phase lines in the northwest-southeast direction along with cellular patterns. When compared with the CTL experiment, stronger updrafts and downdrafts are produced in the NEW experiment.
The maximum velocities of the updrafts in the CTL and NEW experiments are approximately 4.88 and $6.47 \mathrm{~m} \mathrm{~s}^{-1}$, respectively, and the maximum velocities of the downdrafts in the CTL and NEW experiments are approximately 2.71 and $2.81 \mathrm{~m} \mathrm{~s}^{-1}$, respectively. The power spectra densities of vertical velocity from the CTL and NEW experiments are calculated as a 


\section{Vertical velocity at $z=\mathbf{~} \mathbf{~ m ~}$ (a) CTL}

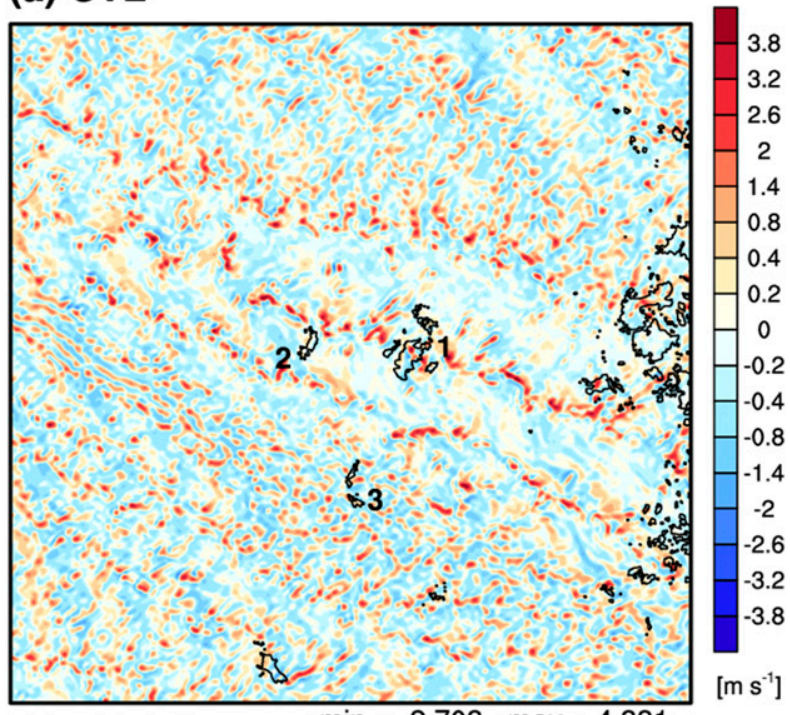

(b) NEW

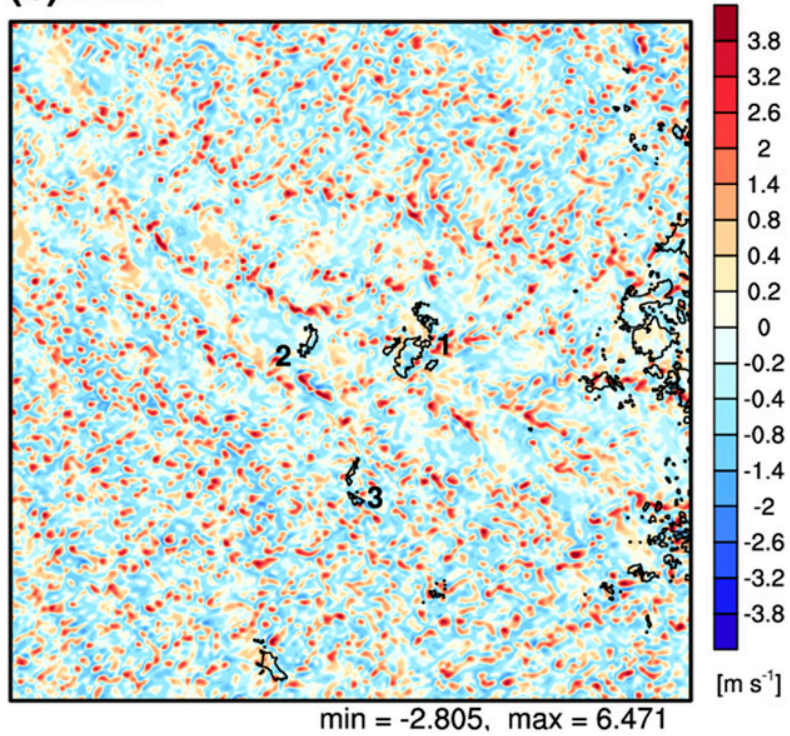

FIG. 5. Vertical velocity $\left(\mathrm{m} \mathrm{s}^{-1}\right)$ at $z=1 \mathrm{~km}$ from the (a) CTL and (b) NEW experiments in the 333-m-resolution analysis domain at 0700 UTC 19 Dec 2013.

function of zonal wavelength at each latitude, and the spectra averaged in the latitudinal direction are displayed in Fig. 6. The dominant zonal wavelength is in the range of $2-10 \mathrm{~km}$ in both experiments; however, the power is larger in the NEW experiment than in the CTL experiment, throughout most of the spectral range. The strengthened vertical motions in the NEW experiment are due to the modified vertical turbulent mixing through the consideration of scale awareness, and it affects the precipitation by changing

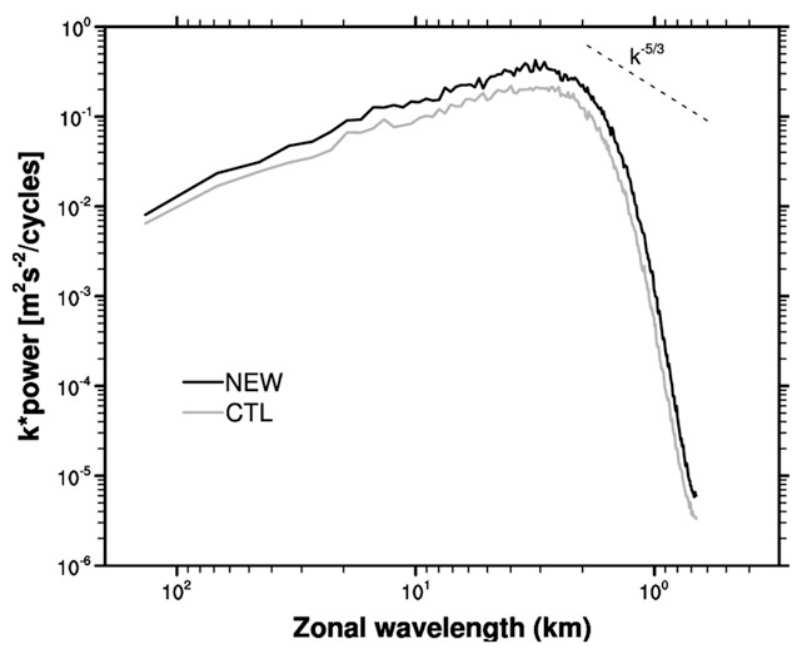

FIG. 6. Latitudinal averages of power spectra density $\left(\mathrm{m}^{2} \mathrm{~s}^{-2}\right.$ cycles $^{-1}$ ) of vertical velocity at $z=1 \mathrm{~km}$ as a function of zonal wavelength calculated at each latitude from the CTL (gray solid line) and NEW (black solid line) experiments in the 333-m-resolution analysis domain at $0700 \mathrm{UTC} 19 \mathrm{Dec} 2013$. The $k^{-5 / 3}$ powerlaw line is indicated by the black dotted line.

microphysical processes, which is discussed in the following subsections.

Figure 7 shows the time-height cross sections of the differences in water vapor mixing ratio and potential temperature averaged over the 333-m-resolution analysis domain between the NEW and CTL experiments. The vertical profiles of the differences at 0700 UTC 19 December 2013 are also displayed. Compared with the CTL experiment, the mixing ratio of water vapor in the NEW experiment is smaller below and near the PBL top and is larger above the PBL top. Two additional sets of experiments are performed with different initial conditions at 0600 UTC 18 December and 1800 UTC 17 December 2013, which are initialized $6 \mathrm{~h}$ later and $6 \mathrm{~h}$ earlier than the control experiment, respectively. It is found that the drier air below and near the PBL top and wetter air above the PBL top in the NEW experiment than the CTL experiment are systematic regardless of the initial condition, and the degree of sensitivity to the PBL schemes with and without scale awareness is comparable to that to initial condition (not shown). The potential temperature in the NEW experiment is generally warmer near the surface, colder below the PBL top, warmer again in the entrainment zone, and colder above it when compared with that in the CTL experiment. The mostly colder air in the PBL stabilizes the layer; thus, the PBL top becomes lower in the NEW experiment than in the CTL experiment. Note that the maximum differences in water vapor mixing ratio and potential temperature between the two experiments are $0.066 \mathrm{~g} \mathrm{~kg}^{-1}$ and $0.12 \mathrm{~K}$, respectively, and this leads to an 
(a) Water vapor (NEW-CTL)

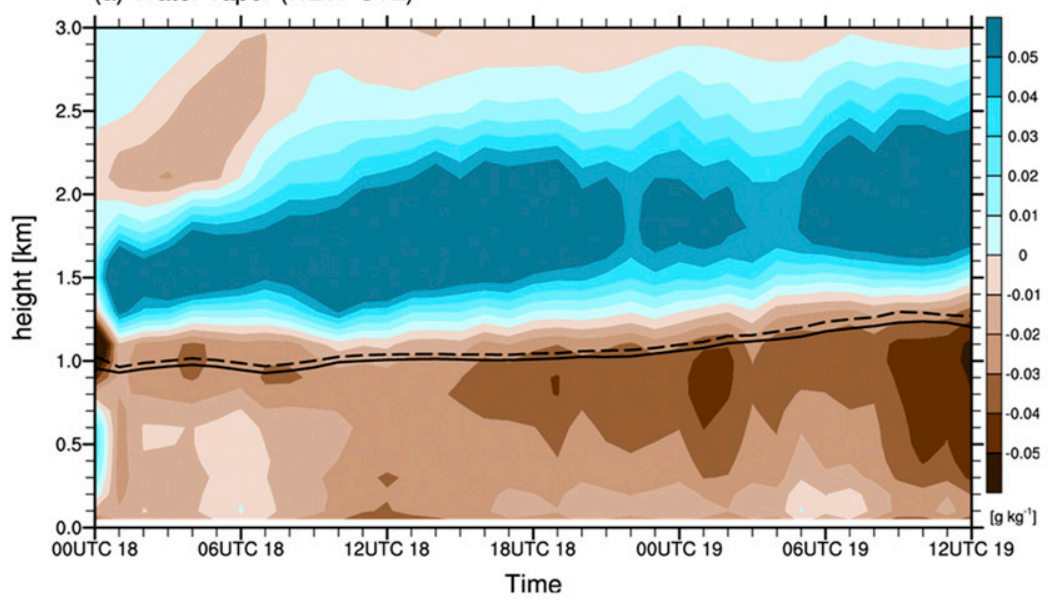

(b) Potential temperature (NEW-CTL)

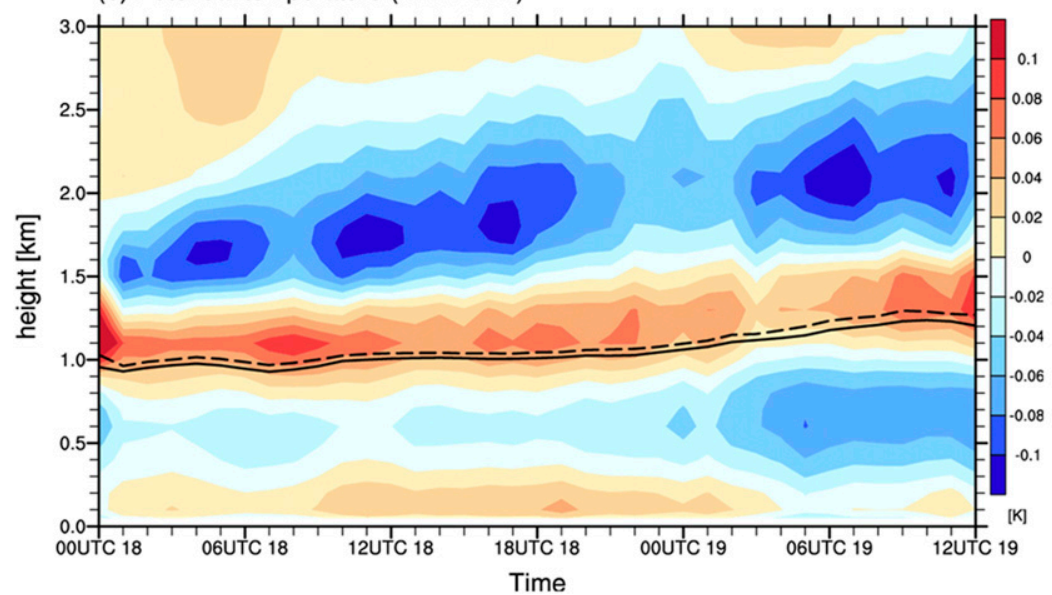

0700 UTC 19

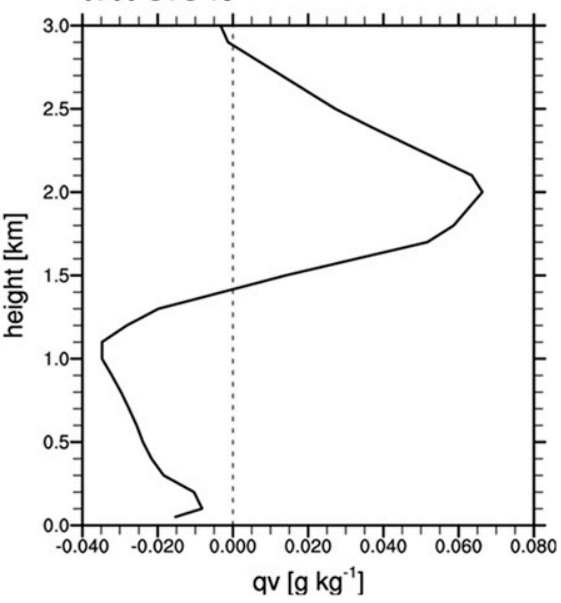

0700 UTC 19

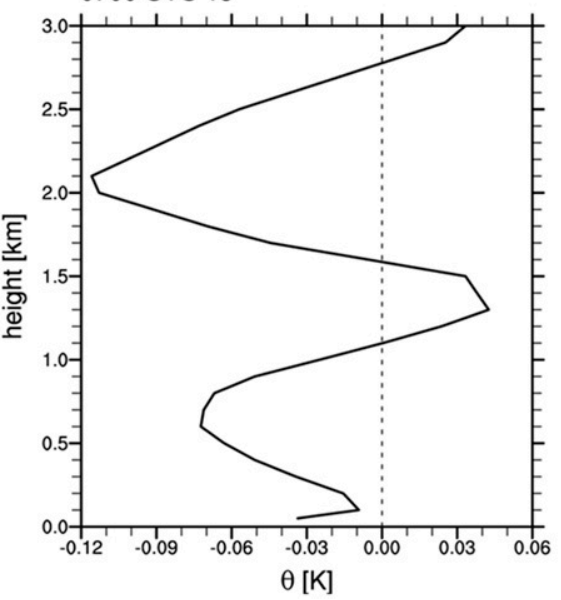

FIG. 7. Time-height cross sections of the differences in (a) water vapor mixing ratio $\left(\mathrm{g} \mathrm{kg}^{-1}\right)$ and (b) potential temperature (K) averaged over the 333-m-resolution analysis domain between the NEW and CTL experiments. The heights of the PBL in the CTL and NEW experiments are indicated by black dashed and solid lines, respectively. The vertical profiles of the differences at 0700 UTC 19 Dec 2013 are displayed in the panels on the right.

approximately $10 \%$ change $\left(0.025 \mathrm{~mm} \mathrm{day}^{-1}\right)$ in precipitation rate (Fig. 4b). The differences in water vapor mixing ratio and potential temperature are understood by the combinations of their differences through the turbulent and microphysical processes, which is now discussed in sections $4 \mathrm{~b}$ and $4 \mathrm{c}$. Although the turbulent processes in practice interact with other processes such as shallow convection, it is found that the interactions are negligible is this study.

\section{b. Turbulent characteristics}

Figure 8 shows the vertical profiles of the parameterized and resolved turbulent moisture and heat fluxes averaged over the 333-m-resolution analysis domain from the CTL and NEW experiments, as well as their differences. In both the CTL and NEW experiments, the parameterized turbulent moisture fluxes are strongest at the surface, decrease with height, and become nearly zero near $z=2 \mathrm{~km}$. The resolved turbulent moisture fluxes are zero at the surface, increase with height, are maximized near the PBL top, and decrease above it. In comparison with the CTL experiment, the parameterized moisture flux is reduced, but the resolved flux is enhanced in the NEW experiment. The parameterized turbulent heat fluxes in both the CTL and NEW experiments are strongest at the surface, decrease with height, and have negative values in the entrainment zone. The magnitude of resolved heat fluxes is mostly smaller than that of parameterized fluxes, with a zero value at the surface, maximum near $z=0.3 \mathrm{~km}$, and local minimum value near the PBL top. Unlike the parameterized fluxes, the positive resolved heat fluxes appear in the entrainment zone below approximately $z=1.9 \mathrm{~km}$, and nonzero negative fluxes also occur above 
(a) Parameterized turbulent moisture flux

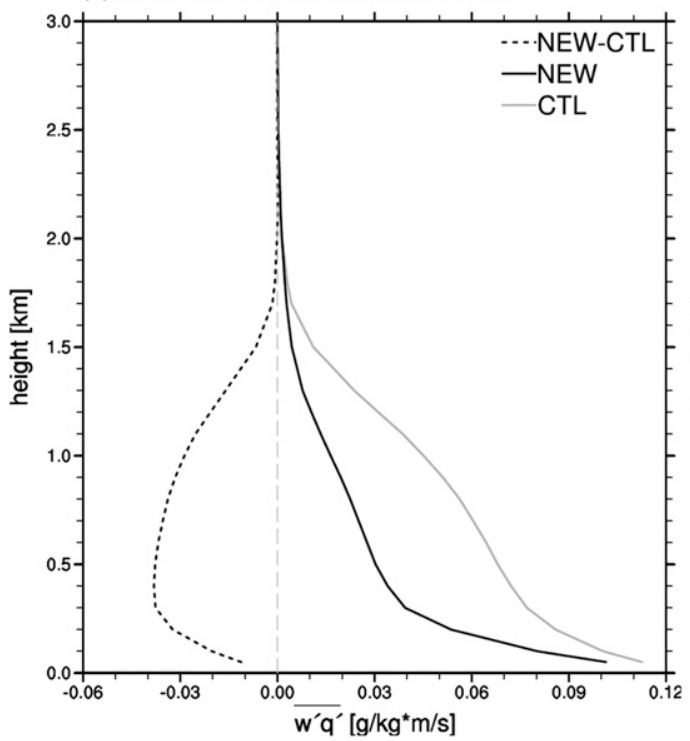

(b) Resolved turbulent moisture flux

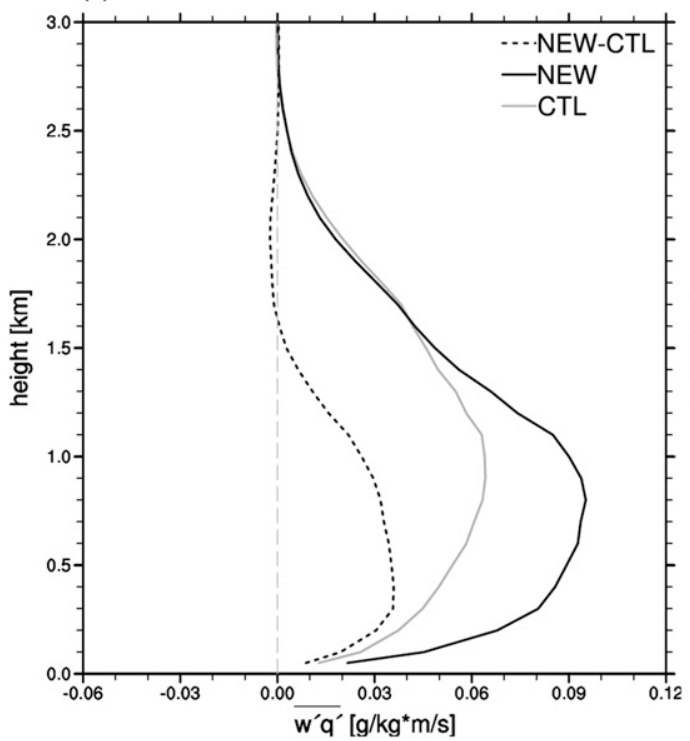

(c) Parameterized turbulent heat flux

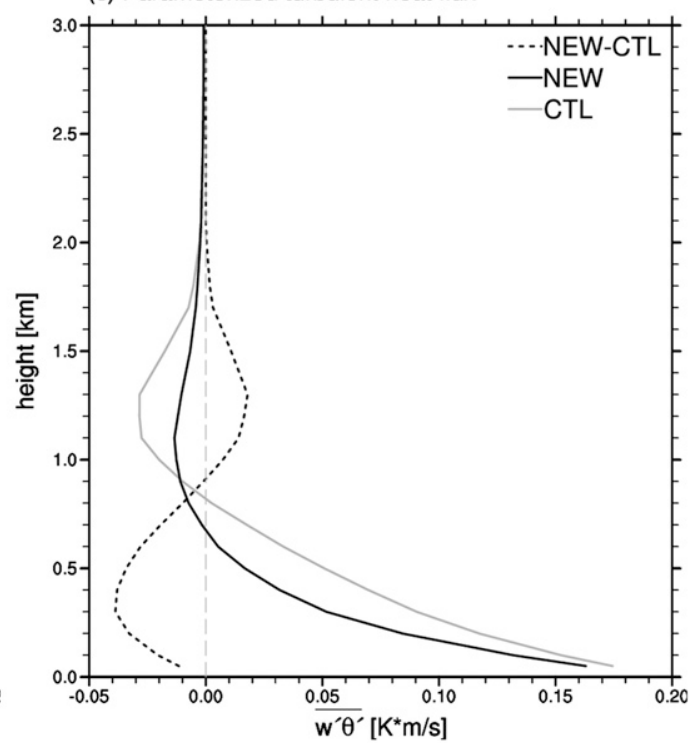

(d) Resolved turbulent heat flux

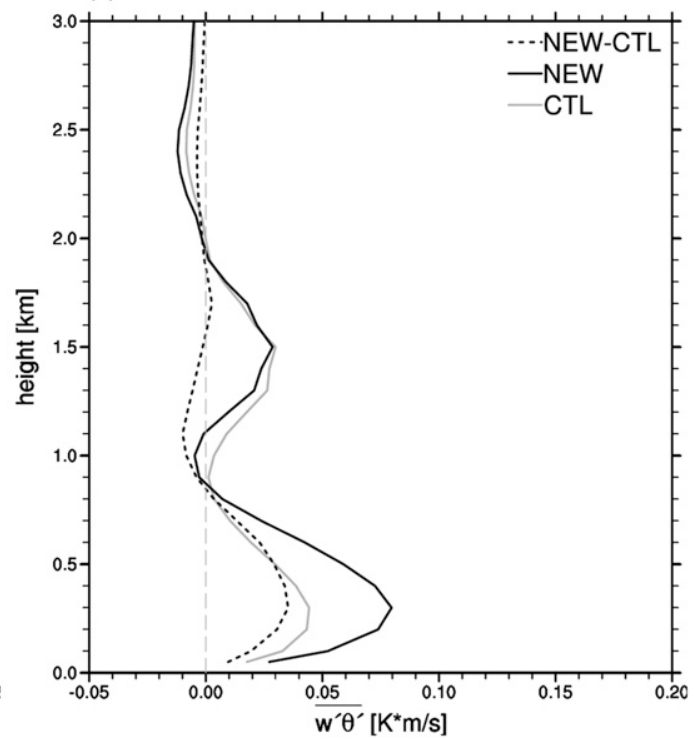

FIG. 8. Vertical profiles of (a),(c) parameterized and (b),(d) resolved turbulent (left) moisture fluxes $\left(\mathrm{g} \mathrm{kg}^{-1} \mathrm{~m} \mathrm{~s}^{-1}\right)$ and (right) heat fluxes $\left(\mathrm{K} \mathrm{m} \mathrm{s}^{-1}\right)$ from the CTL (gray solid line) and NEW (black solid line) experiments, and the differences (black dotted line) between the NEW and CTL experiments in the 333-m-resolution analysis domain at 0700 UTC 19 Dec 2013. The zero line is indicated by the vertical gray dashed line.

it, which are likely associated with large-scale eddies in the clouds developed above the PBL. Like the moisture flux, the parameterized heat flux is reduced, but the resolved flux is enhanced in the NEW experiment compared with that in the CTL experiment. The difference between the resolved and unresolved parameterized fluxes can be related to the factors such as model resolution and PBL parameterization used in the model (Shin and Dudhia 2016). Note that none of PBL parameterization schemes is scale aware in Shin and Dudhia (2016). With the scale-aware PBL scheme, the vertical structures of the resolved and parameterized fluxes and their difference also can be dependent on how scale awareness is represented in the PBL scheme. The parameterized flux is directly controlled by the grid size dependency function represented in the scaleaware scheme, which indirectly affects the resolved flux by modulating the resolved-scale motions as shown in Figs. 5-7. 
(a) qv tendency (NEW-CTL)

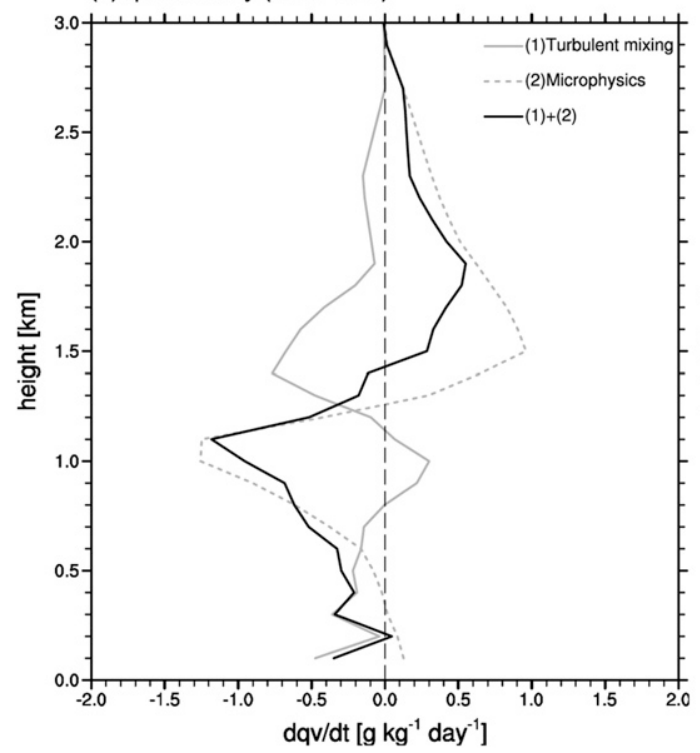

(b) $\theta$ tendency (NEW-CTL)

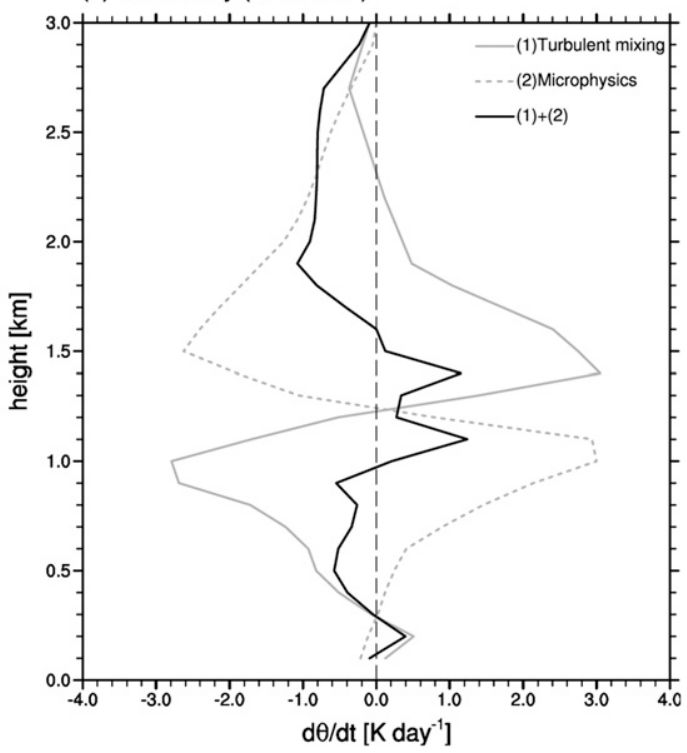

FIG. 9. Vertical profiles of the differences in (a) water vapor mixing ratio tendencies $\left(\mathrm{g} \mathrm{kg}^{-1} \mathrm{day}^{-1}\right)$ and (b) potential temperature tendencies $\left(\mathrm{K} \mathrm{day}^{-1}\right)$ due to turbulent mixing (gray solid line) and microphysical (gray dotted line) processes and their sum (black solid line) between the NEW and CTL experiments in the 333-mresolution analysis domain at 0700 UTC 19 Dec 2013. The zero line is indicated by the vertical gray dashed line.

Figure 8 also displays the differences in the parameterized fluxes and those in the resolved fluxes between the two experiments, which mostly cancel each other. Because an increase (a decrease) in the decreasing (increasing) rate of the moisture flux with height leads to the moistening of the air according to Eqs. (1) and (2), the difference in the parameterized (resolved) moisture flux (Figs. 8a,b) indicates that the air in the NEW experiment becomes wetter (drier) below approximately $z=0.3 \mathrm{~km}$ and drier (wetter) above this level than that in the CTL experiment. The combined effect of the differences in the parameterized and resolved moisture fluxes is shown in Fig. 9a, which displays the difference in the tendency of the water vapor mixing ratio due to both the parameterized and resolved turbulent mixing between the NEW and CTL experiments. The difference in moisture tendency shows that the air becomes mostly drier to $z=0.8 \mathrm{~km}$ from the surface, wetter at approximately $z=0.8-1.2 \mathrm{~km}$, and drier above it in the NEW experiment compared with that in the CTL experiment. In Figs. 8c and 8d, the difference in the parameterized heat flux indicates that the air becomes warmer below approximately $z=0.3 \mathrm{~km}$, colder at approximately $z=0.3-1.3 \mathrm{~km}$, and warmer again above it in the NEW experiment than that in the CTL experiment. Because of the resolved heat flux, the air in the NEW experiment becomes colder below approximately $z=0.3 \mathrm{~km}$, warmer at approximately $z=0.3-1.1 \mathrm{~km}$, and colder above it than that in the CTL experiment.
The combined contribution of the differences in both the parameterized and resolved turbulent heat fluxes to potential temperature, which is displayed by a gray solid line in Fig. 9b, indicates that the temperature rises near the surface, is lowered at approximately $z=0.3-$ $1.25 \mathrm{~km}$, and rises again above it. However, the differences in water vapor mixing ratio and potential temperature between the NEW and CTL experiments shown in Fig. 7 cannot be explained only by the differences in the moisture and temperature tendencies due to the turbulent process. They need to be understood through the interaction with the effects due to microphysical processes, which is now discussed in section $4 \mathrm{c}$.

\section{c. Microphysical characteristics}

Figure 10 shows the liquid and ice water paths from the CTL and NEW experiments. Both experiments simulate roll-type clouds, which are organized in the form of elongated bands and are aligned parallel to northwesterly mean winds, as well as cellular cloud patterns. The regions of high liquid water content are collocated with the strong updraft regions (see Fig. 5), where supersaturation and, therefore, condensation occur through the adiabatic cooling of the air. The amount of ice-phase hydrometeors is approximately 4.7 and 3.4 times as large as that of liquid-phase hydrometeors in the CTL and NEW experiments, respectively, in this wintertime precipitation case. 


\section{Liquid water path (0700 UTC 19)}

(a) CTL

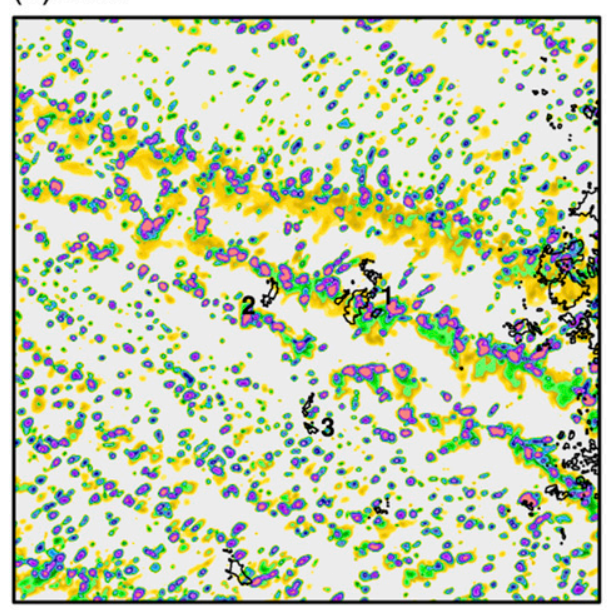

(b) NEW

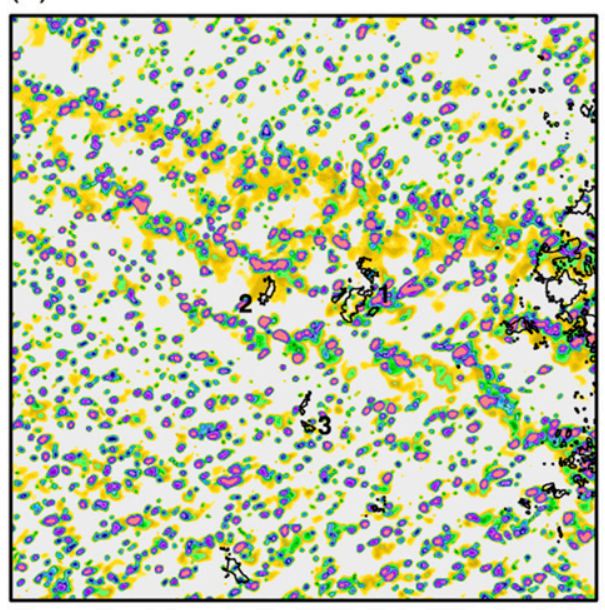

avg = 25.6183 (CTL), 32.9134 (NEW)
Ice water path (0700 UTC 19)

(c) CTL
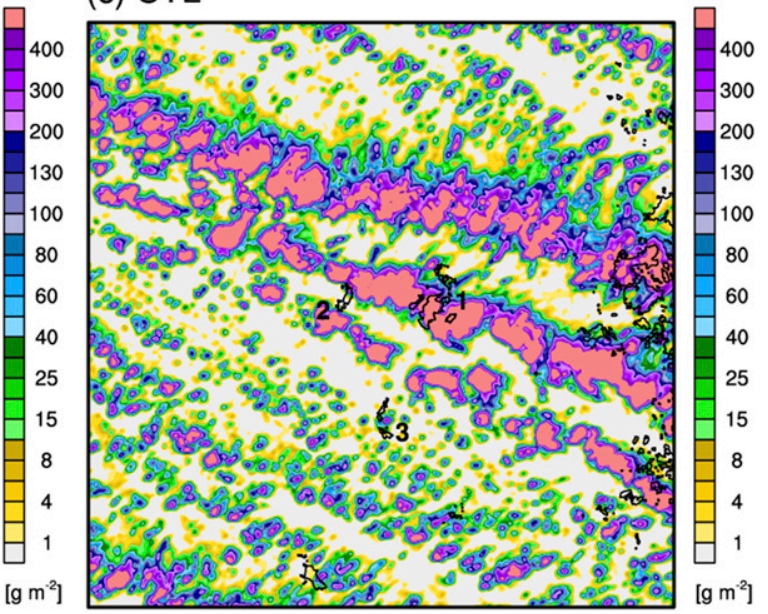

(d) NEW
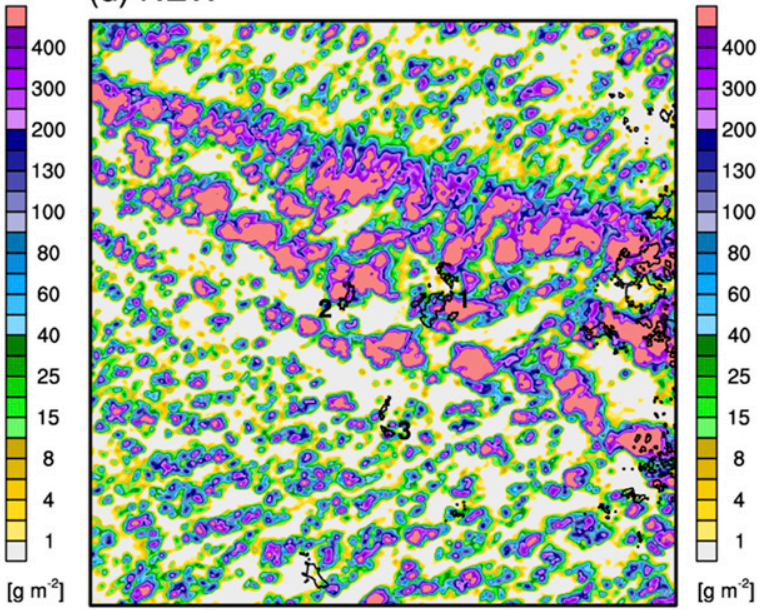

avg = $119.83(\mathrm{CTL}), 111.982$ (NEW)

FIG. 10. (a),(b) Liquid and (c),(d) ice water paths $\left(\mathrm{g} \mathrm{m}^{-2}\right)$ from the (top) CTL and (bottom) NEW experiments in the 333-m-resolution analysis domain at 0700 UTC 19 Dec 2013.

The NEW experiment produces higher liquid water content than that of the CTL experiment, while lower ice water content. Note that the liquid (ice) water paths averaged over the 333-m-resolution analysis domain at 0700 UTC 19 December 2013 are approximately 25.6 (119.8) and 32.9 (112.0) $\mathrm{g} \mathrm{m}^{-2}$ in the CTL and NEW experiments, respectively. The vertical profiles of the content of each hydrometeor and their sum averaged over the 333-m-resolution domain at 0700 UTC 19 December 2013 are shown in Fig. 11. It is clearly seen that the cloud and rainwater contents are higher in the NEW experiment than those in the CTL experiment (Fig. 11b). On the contrary, lower cloud ice and snow contents are observed in the NEW experiment (Fig. 11c). Because the increase in liquid water content is greater than the decrease in ice water content, the total hydrometeor content in the NEW experiment is higher on average than that in the CTL experiment (Fig. 11a).

Figure 12 shows the vertical profiles of condensation and evaporation rates of cloud water, rates of autoconversion from cloud water to rainwater and accretion of cloud water by rainwater, and evaporation rate of rainwater obtained from the CTL and NEW experiments, along with their differences. The stronger updraft in the NEW experiment (see Fig. 5) leads to enhanced condensation (Fig. 12a), causing a larger amount of cloud water within the cloud. This enhances the autoconversion and accretion processes from cloud water to rainwater (Fig. 12b), producing more rainwater. Both the increased cloud water content available for evaporation and the reduced adiabatic warming resulting from the weakened vertical velocity in the upper part of the 
(a) Total $(q c+q i+q r+q s)$

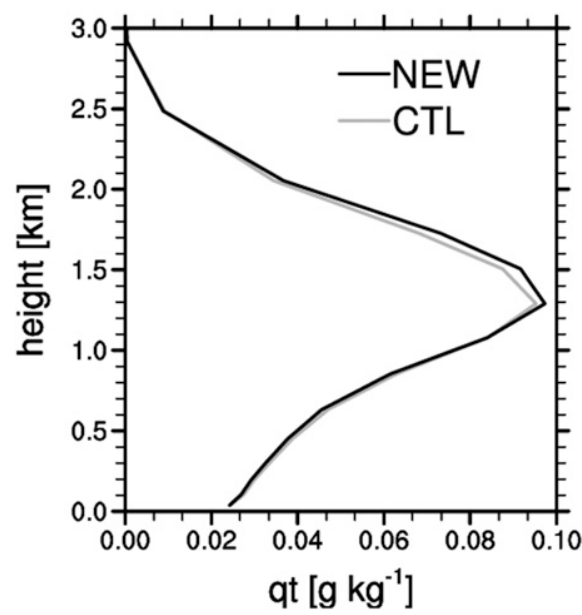

(b) Cloud/Rain water

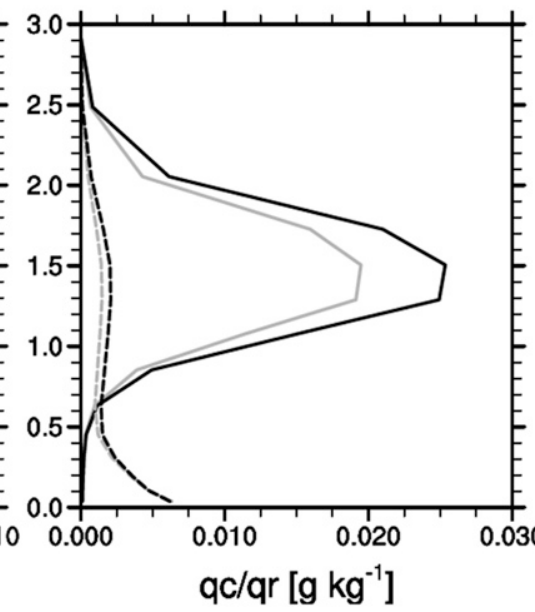

(c) Cloud ice/Snow

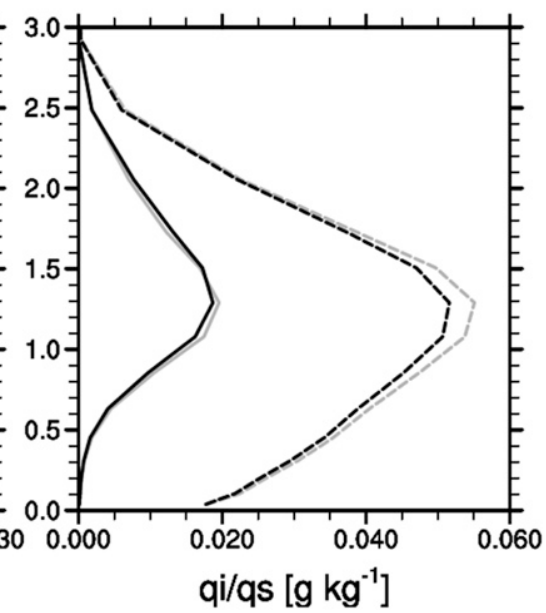

FIG. 11. Vertical profiles of (a) total hydrometeor, (b) cloud (solid line) and rain (dashed line) water, and (c) cloud ice (solid line) and snow (dashed line) contents $\left(\mathrm{g} \mathrm{kg}^{-1}\right)$ averaged over the 333-m-resolution domain at 0700 UTC 19 Dec 2013 from the CTL (gray lines) and NEW (black lines) experiments.

updraft above approximately $z=1.5 \mathrm{~km}$ (not shown) increase the evaporation rate of cloud water there in the NEW experiment. Similarly, both the increased mass available for evaporation and the drier PBL (see Fig. 7a) result in an increase in the evaporation rate of rainwater in the lower atmosphere (Fig. 12c).

The vertical profiles of deposition and sublimation rates of cloud ice and snow, rates of aggregation of cloud ice to snow and accretion of cloud ice by rainwater, and snow melting rate are plotted in Fig. 13. Because the atmosphere below and near the PBL top is drier in the NEW experiment, the deposition process of cloud ice is suppressed, and the sublimation process is enhanced in the layer between $z=0.7$ and $1.6 \mathrm{~km}$ (Fig. 13a), resulting in lower cloud ice water content. This, in turn, leads to the suppressed growth of cloud ice to snow by aggregation and accretion processes (Fig. 13c), contributing to a smaller amount of snow. Reduction in the snow content is also caused by the suppression (enhancement) of the deposition (sublimation) process of snow (Fig. 13b) due to the drier air below and near the PBL top. Note that the decreased sublimation rate of cloud ice below $z=0.7 \mathrm{~km}$ in the NEW experiment is attributable to the moistening resulting from (a) condensation/evaporation

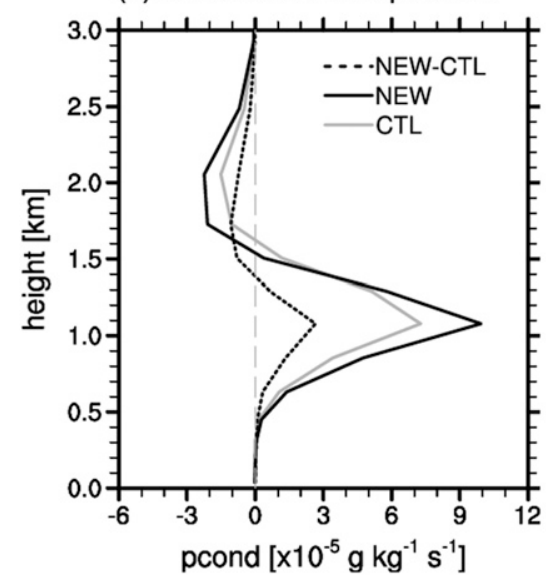

(b) autoconversion/accretion

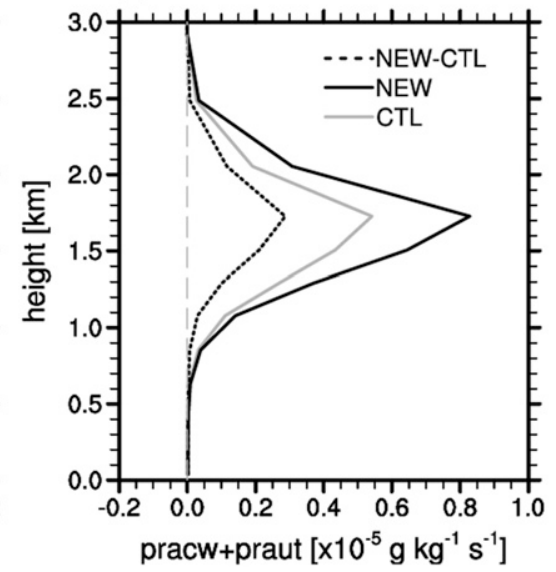

(c) evaporation of qr

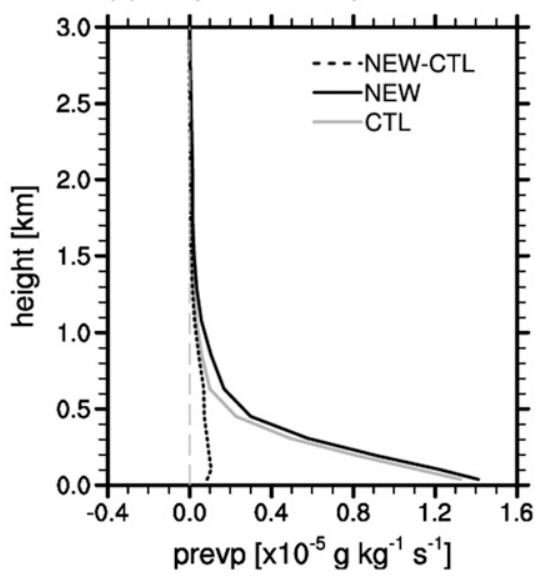

FIG. 12. Vertical profiles of (a) condensation and evaporation rates of cloud water $\left(\mathrm{g} \mathrm{kg}^{-1} \mathrm{~s}^{-1}\right)$, (b) autoconversion and accretion rates of cloud water to rainwater $\left(\mathrm{g} \mathrm{kg}^{-1} \mathrm{~s}^{-1}\right)$, and (c) evaporation rate of rainwater $\left(\mathrm{g} \mathrm{kg}^{-1} \mathrm{~s}^{-1}\right)$ averaged over the 333-m-resolution domain at 0700 UTC 19 Dec 2013 from the CTL (gray solid lines) and NEW (black solid lines) experiments, and the differences (black dotted lines) between the NEW and CTL experiments. The zero line is indicated by the vertical gray dashed line. 
(a) deposition/sublimation of qi

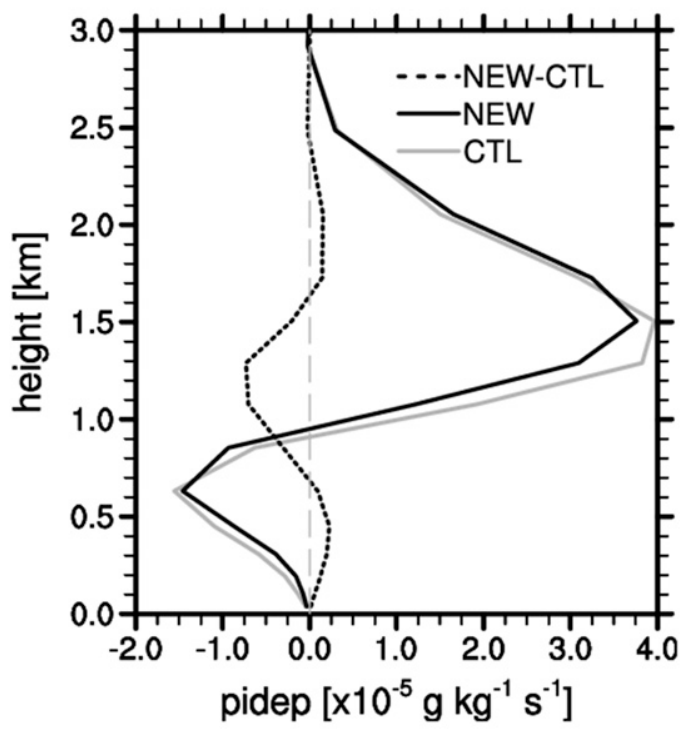

(b) deposition/sublimation of qs

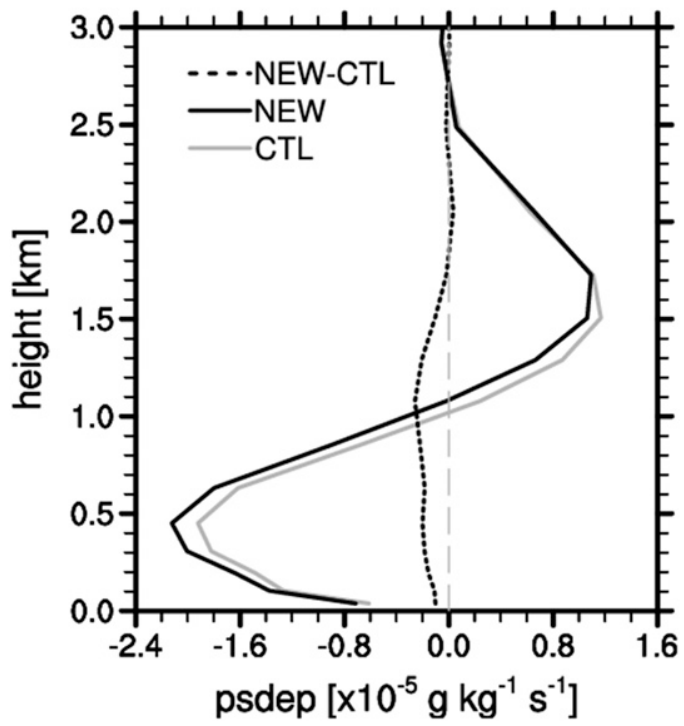

(c) aggregation/accretion

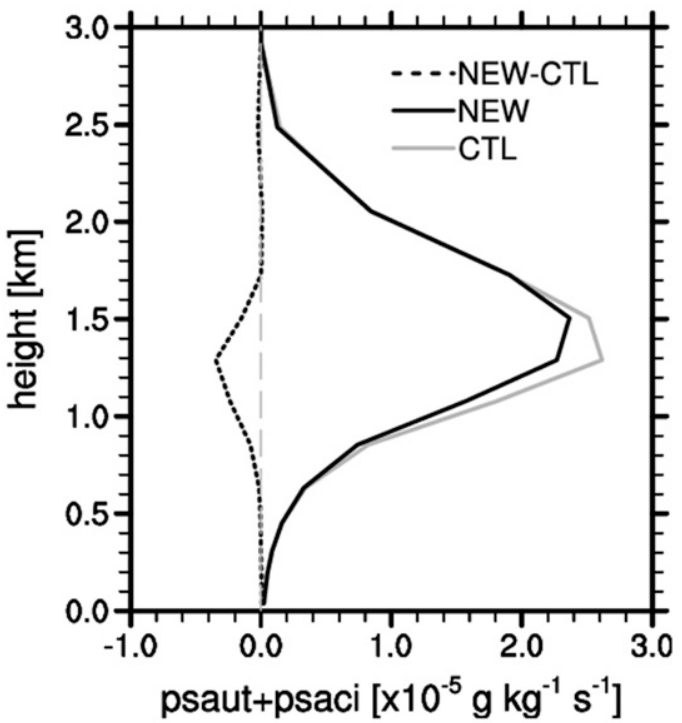

(d) snow melting

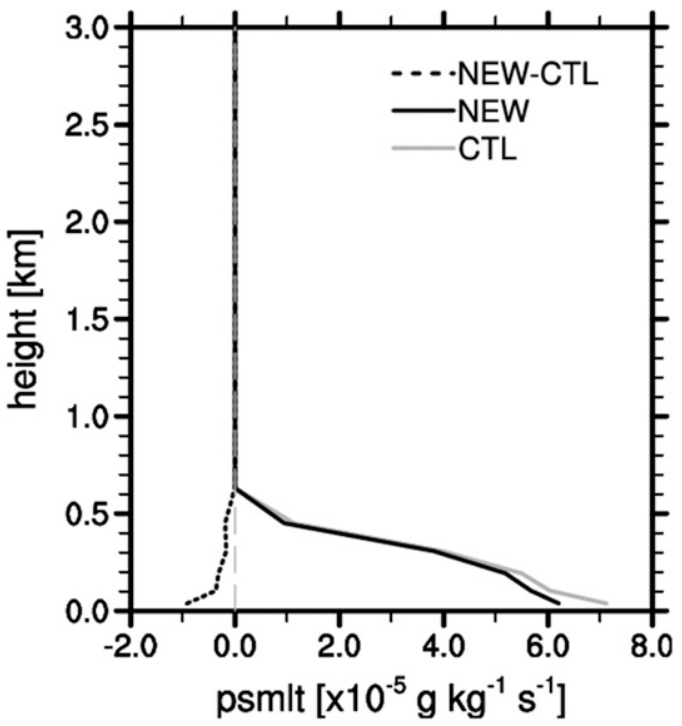

FIG. 13. Vertical profiles of deposition and sublimation rates of (a) cloud ice and (b) snow $\left(\mathrm{g} \mathrm{kg}^{-1} \mathrm{~s}^{-1}\right)$, (c) aggregation and accretion rates of cloud ice to snow $\left(\mathrm{g} \mathrm{kg}^{-1} \mathrm{~s}^{-1}\right)$, and (d) melting rate of snow $\left(\mathrm{g} \mathrm{kg}^{-1} \mathrm{~s}^{-1}\right)$ averaged over the 333-m-resolution domain at 0700 UTC 19 Dec 2013 from the CTL (gray solid lines) and NEW (black solid lines) experiments, and the differences (black dotted lines) between the NEW and CTL experiments. The zero line is indicated by the vertical gray dashed line.

the enhanced evaporation of rainwater. On the other hand, the rate of snow sublimation increases even in the lower layer owing to the drying effect resulting from the suppression of the sublimation process of cloud ice there. The melting of a smaller amount of snow (Fig. 13d) leads to a decrease in the amount of surface precipitation in the NEW experiment (see Fig. 4).

The vertical profiles of the differences in the tendencies of water vapor mixing ratio and potential temperature due to microphysical processes between the NEW and CTL experiments are shown in Fig. 9, indicating that the atmosphere below $z=0.3 \mathrm{~km}$ and above $z=1.25 \mathrm{~km}$ becomes moister and colder in the NEW experiment than that in the CTL experiment mainly because of the enhanced evaporation of rainwater and cloud water, respectively, and the air between them becomes drier and warmer mostly because of the more active condensation process. The black solid line in Fig. 9 corresponds to the 


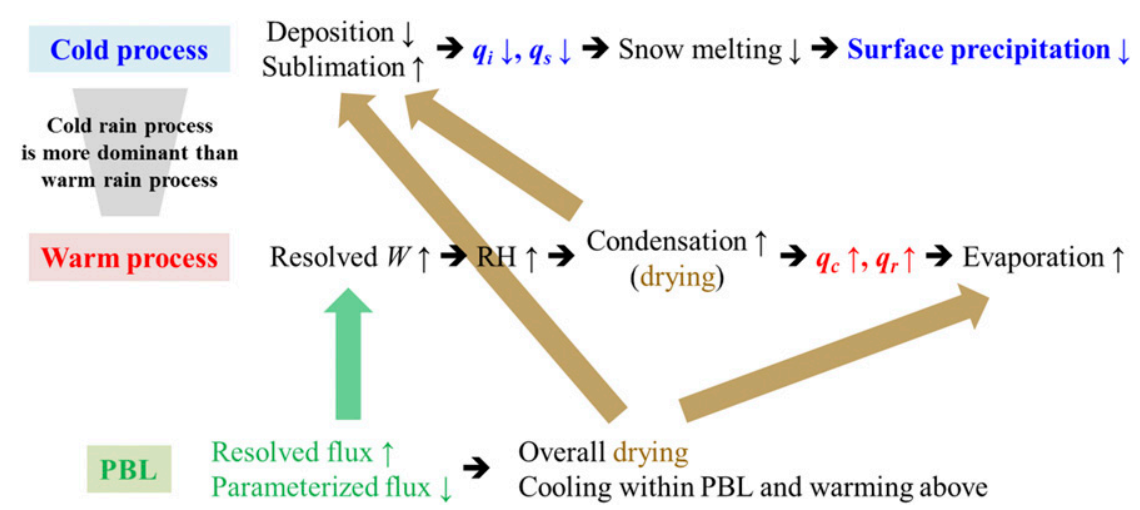

FIG. 14. A schematic diagram of how the differences in turbulent transport between the SH and YSU schemes affect lake-effect precipitation through interaction with microphysical processes.

impact of the combination of turbulent mixing and microphysical processes on the differences in the vertical distribution of moisture and temperature between the two experiments. Their combined effect makes the atmosphere in the NEW experiment drier below and near the PBL top and wetter above it than that in the CTL experiment (see Fig. 7a). Also, it induces the warming of the air near the surface and in the entrainment zone and the cooling within the PBL and above the entrainment zone (see Fig. 7b).

\section{Summary and conclusions}

This study examined the impact of a scale-aware nonlocal PBL scheme on a wintertime lake-effect precipitation event over Korea at gray-zone resolutions. For this purpose, we performed an experiment using the WRF Model with the SH scheme (Shin and Hong 2013, 2015) adopting scale awareness in the parameterization of the vertical transport of subgridscale turbulent fluxes and compared the results with those obtained using the YSU scheme without the scale-aware capability. The schematic diagram of Fig. 14 illustrates how the differences in turbulent transport between the two experiments affect clouds and precipitation through interaction with microphysical processes. The consideration of grid-size dependency in the experiment with the SH scheme reduces the parameterized turbulent flux, but enhances the resolved one, which causes strengthened vertical motions. The increased adiabatic cooling in the strong updraft region leads to enhanced condensation and, therefore, higher cloud water content. This results in the enhanced growth of cloud water to rainwater by autoconversion and accretion processes, producing a larger amount of rainwater. On the contrary, the amount of cloud ice is reduced, mainly because the drier PBL, which results from the decreased parameterized but increased resolved turbulent moisture fluxes and enhanced condensation, contributes to the suppression of the deposition process and enhancement of the sublimation process of cloud ice. This, in turn, reduces the amount of snow not only by suppressing the snow deposition process and enhancing the snow sublimation process, but also by suppressing the aggregation and accretion processes from cloud ice to snow. The melting of a smaller amount of snow in the experiment with the scale-aware PBL scheme leads to the suppression of the wintertime lake-effect precipitation at a gray-zone resolution. The interactions between changes in the turbulent processes from the use of the scale-aware PBL scheme and the microphysical processes can be highly dependent on cloud type and environmental conditions. The effects of the scale-aware PBL scheme on different cloud types, such as severe storms and squall lines, developed under different thermodynamic conditions will be investigated in future studies.

Acknowledgments. The authors thank Song-You Hong and Sang-Hoon Yeon for their valuable comments. We are also thankful to two anonymous reviewers for their constructive comments to improve this paper. This work has been carried out through the R\&D project on the development of global numerical weather prediction systems of the KIAPS funded by the Korea Meteorological Administration (KMA). This work was also supported by KMA2018-00721, "Development of Numerical Weather Prediction and Data Application Techniques," of the Numerical Modeling Center of the KMA and the National Research Foundation of Korea (NRF) grant funded by the Korea government (Ministry of Science and ICT) (2017R1E1A1A01074889). 


\section{REFERENCES}

Baek, S., 2017: A revised radiation package of G-packed McICA and two-stream approximation: Performance evaluation in a global weather forecasting model. J. Adv. Model. Earth Syst., 9, 1628-1640, https://doi.org/10.1002/2017MS000994.

Boutle, I. A., J. E. J. Eyre, and A. P. Lock, 2014: Seamless stratocumulus simulation across the turbulent gray zone. Mon. Wea. Rev., 142, 1655-1668, https://doi.org/10.1175/MWR-D-13-00229.1.

Bryan, G. H., J. C. Wyngaard, and J. M. Fritsch, 2003: Resolution requirements for the simulation of deep moist convection. Mon. Wea. Rev., 131, 2394-2416, https://doi.org/10.1175/15200493(2003)131<2394:RRFTSO > 2.0.CO;2.

Chen, F., and J. Dudhia, 2001: Coupling and advanced land surface-hydrology model with the Penn State-NCAR MM5 modeling system. Part I: Model implementation and sensitivity. Mon. Wea. Rev., 129, 569-585, https://doi.org/10.1175/ 1520-0493(2001)129<0569:CAALSH>2.0.CO;2.

Ching, J., R. Rotunno, M. A. LeMone, A. Martilli, B. Kosovic, P. A. Jimenez, and J. Dudhia, 2014: Convectively induced secondary circulations in fine-grid mesoscale numerical weather prediction models. Mon. Wea. Rev., 142, 3284-3302, https://doi.org/10.1175/MWR-D-13-00318.1.

Deardorff, J. W., 1972: Theoretical expression for the countergradient vertical heat flux. J. Geophys. Res., 77, 5900-5904, https://doi.org/10.1029/JC077i030p05900.

Doubrawa, P., A. Montornès, R. J. Barthelmie, S. C. Pryor, and P. Casso, 2018: Analysis of different gray-zone treatments in WRF-LES real case simulations. Wind Energ. Sci. Discuss., https://doi.org/10.5194/WES-2017-61, in press.

Efstathiou, G. A., and R. J. Beare, 2015: Quantifying and improving sub-grid diffusion in the boundary-layer grey zone. Quart. J. Roy. Meteor. Soc., 141, 3006-3017, https://doi.org/ 10.1002/qj.2585.

Fiori, E., A. Parodi, and F. Siccardi, 2009: Dealing with uncertainty: Turbulent parameterizations and grid-spacing effects in numerical modelling of deep moist convective processes. Nat. Hazards Earth Syst. Sci., 9, 1871-1880, https://doi.org/10.5194/ nhess-9-1871-2009.

Han, J., and H.-L. Pan, 2011: Revision of convection and vertical diffusion schemes in the NCEP global forecast system. Wea. Forecasting, 26, 520-533, https://doi.org/10.1175/WAF-D-1005038.1 .

Han, J.-Y., S.-Y. Hong, K.-S. S. Lim, and J. Han, 2016: Sensitivity of a cumulus parameterization scheme to precipitation production representation and its impact on a heavy rain event over Korea. Mon. Wea. Rev., 144, 2125-2135, https://doi.org/ 10.1175/MWR-D-15-0255.1.

,-- , and Y. C. Kwon, 2020: The performance of a revised simplified Arakawa-Schubert (SAS) convection scheme in the medium-range forecasts of the Korean Integrated Model (KIM). Wea. Forecasting, 35, 1113-1128, https://doi.org/ 10.1175/WAF-D-19-0219.1.

Holtslag, A. A. M., and C.-H. Moeng, 1991: Eddy diffusivity and countergradient transport in the convective atmospheric boundary layer. J. Atmos. Sci., 48, 1690-1698, https://doi.org/ 10.1175/1520-0469(1991)048<1690:EDACTI >2.0.CO;2.

Hong, S.-Y., and J. Jang, 2018: Impacts of shallow convection processes on a simulated boreal summer climatology in a global atmospheric model. Asia-Pac. J. Atmos. Sci., 54, 361370, https://doi.org/10.1007/s13143-018-0013-3.

— J. Judhia, and S.-H. Chen, 2004: A revised approach to ice microphysical processes for the bulk parameterization of clouds and precipitation. Mon. Wea. Rev., 132, 103-120, https:// doi.org/10.1175/1520-0493(2004)132<0103:ARATIM>2.0.CO;2. Y. Noh, and J. Dudhia, 2006: A new vertical diffusion package with an explicit treatment of entrainment processes. Mon. Wea. Rev., 134, 2318-2341, https://doi.org/ 10.1175/MWR3199.1.

Honnert, R., V. Masson, and F. Couvreux, 2011: A diagnostic for evaluating the representation of turbulence in atmospheric models at the kilometric scale. J. Atmos. Sci., 68, 3112-3131, https://doi.org/10.1175/JAS-D-11-061.1.

- F. Couvreux, V. Masson, and D. Lancz, 2016: Sampling the structure of convective turbulence and implications for greyzone parametrizations. Bound.-Layer Meteor., 160, 133-156, https://doi.org/10.1007/s10546-016-0130-4.

Iacono, M.-J., J. S. Delamere, E. J. Mlawer, M. W. Shepherd, S. A. Clough, and W. D. Collins, 2008: Radiative forcing by longlived greenhouse gases: Calculation with the AER radiative transfer models. J. Geophys. Res., 113, D13103, https://doi.org/ 10.1029/2008JD009944.

Ito, J., H. Niino, M. Nakanishi, and C.-H. Moeng, 2015: An extension of the Mellor-Yamada model to the terra incognita zone for dry convective mixed layers in the free convection regime. Bound.-Layer Meteor., 157, 23-43, https://doi.org/ 10.1007/s10546-015-0045-5.

Kurowski, M., and J. Teixeira, 2018: A scale-adaptive turbulent kinetic energy closure for the dry convective boundary layer. J. Atmos. Sci., 75, 675-690, https://doi.org/10.1175/JAS-D-16-0296.1.

Kwon, Y.-C., and S.-Y. Hong, 2017: A mass-flux cumulus parameterization scheme across gray-zone resolutions. Mon. Wea. Rev., 145, 583-598, https://doi.org/10.1175/MWR-D-16-0034.1.

LeMone, A., F. Chen, M. Tewari, J. Dudhia, B. Geerts, Q. Miao, R. L. Coulter, and R. L. Grossman, 2010: Simulating the IHOP_2002 fair-weather CBL with the WRF-ARW-Noah modeling system. Part II: Structures from a few kilometers to $100 \mathrm{~km}$ across. Mon. Wea. Rev., 138, 745-764, https://doi.org/ 10.1175/2009MWR3004.1.

Pergaud, J., V. Masson, S. Malardel, and F. Couvreux, 2009: A parameterization of dry thermals and shallow cumuli for mesoscale numerical weather prediction. Bound.-Layer Meteor., 132, 83-106, https://doi.org/10.1007/s10546-009-9388-0.

Petch, J. C., A. R. Brown, and M. E. B. Gray, 2002: The impact of horizontal resolution on the simulations of convective development over land. Quart. J. Roy. Meteor. Soc., 128, 2031-2044, https://doi.org/10.1256/003590002320603511.

Shin, H. H., and S.-Y. Hong, 2013: Analysis of resolved and parameterized vertical transports in convective boundary layers at gray-zone resolutions. J. Atmos. Sci., 70, 3248-3261, https:// doi.org/10.1175/JAS-D-12-0290.1.

_, and — 2015: Representation of the subgrid-scale turbulent transport in convective boundary layers at gray-zone resolutions. Mon. Wea. Rev., 143, 250-271, https://doi.org/10.1175/ MWR-D-14-00116.1.

_ , and J. Dudhia, 2016: Evaluation of PBL parameterizations in WRF at subkilometer grid spacings: Turbulence statistics in the dry convective boundary layer. Mon. Wea. Rev., 144, 11611177, https://doi.org/10.1175/MWR-D-15-0208.1.

Siebesma, A. P., P. M. M. Soares, and J. Teixeira, 2007: A combined eddy-diffusivity mass-flux approach for the convective boundary layer. J. Atmos. Sci., 64, 1230-1248, https://doi.org/ 10.1175/JAS3888.1.

Skamarock, W. C., and Coauthors, 2008: A description of the Advanced Research WRF version 3. NCAR Tech. Note NCAR/TN475+STR, 113 pp., http://doi.org/10.5065/D68S4MVH. 
Soares, P. M. M., P. M. A. Miranda, A. P. Siebesma, and J. Teixeira, 2004: An eddy-diffusivity/mass-flux parameterization for dry and shallow cumulus convection. Quart. J. Roy. Meteor. Soc., 130, 3365-3383, https://doi.org/ 10.1256/qj.03.223.

Stull, R. B., 1988: An Introduction to Boundary Layer Meteorology. Kluwer Academic, 666 pp.

Thiébaux, J., E. Rogers, W. Wang, and B. Katz, 2003: A new highresolution blended real-time global sea surface temperature analysis. Bull. Amer. Meteor. Soc., 84, 645-656, https://doi.org/ 10.1175/BAMS-84-5-645.
Wyngaard, J. C., 2004: Toward numerical modeling in the "terra incognita." J. Atmos. Sci., 61, 1816-1826, https://doi.org/ 10.1175/1520-0469(2004)061<1816:TNMITT>2.0.CO;2.

$\mathrm{Xu}, \mathrm{H}$., Y. Wang, and M. Wang, 2018: The performance of a scaleaware nonlocal PBL scheme for the sub-kilometer simulation of a deep CBL over the Taklimakan desert. Adv. Meteor., 2018, 8759594, https://doi.org/10.1155/2018/8759594.

Zhou, B., M. Xue, and K. Zhu, 2017: A grid-refinement-based approach for modeling the convective boundary layer in the gray zone: A pilot study. J. Atmos. Sci., 74, 3497-3513, https:// doi.org/10.1175/JAS-D-16-0376.1. 